\title{
Primary tumor surgery improves survival of cancer patients with synchronous solitary bone metastasis: a large population-based study
}

\author{
Wei Wu, Honghua Zhang^, Zhong Fang, Feng Li \\ Department of Orthopaedic Surgery, Tongji Hospital, Tongji Medical College, Huazhong University of Science and Technology, Wuhan, China \\ Contributions: (I) Conception and design: H Zhang, Z Fang, F Li; (II) Administrative support: F Li; (III) Provision of study materials or patients: \\ W Wu, H Zhang; (IV) Collection and assembly of data: W Wu, H Zhang, Z Fang; (V) Data analysis and interpretation: W Wu, H Zhang; (VI) \\ Manuscript writing: All authors; (VII) Final approval of manuscript: All authors. \\ Correspondence to: Feng Li; Zhong Fang; Honghua Zhang. Department of Orthopaedic Surgery, Tongji Hospital, Tongji Medical College, Huazhong \\ University of Science and Technology, Wuhan, China. Email: lifengmd@hust.edu.cn; zhongfangtjh@yahoo.com; zhanghonghua@hust.edu.cn.
}

Background: There is a heated debate on whether or not a late-stage cancer patient with bone metastasis should receive primary surgery. The aim was to assess whether primary tumor surgery in cancer patients with bone metastasis was associated with improved survival.

Methods: Cancer patients with bone metastasis were identified in the Surveillance, Epidemiology, and End Results database between 2010 and 2016. Overall survival and cancer-specific survival were compared between patients with and without primary tumor surgery using risk-adjusted Cox proportional hazard regression models and stratified propensity score methods. Further nomograms were constructed to predict personalized survival.

Results: Overall, 22,631 cancer patients with synchronous bone metastasis were identified and the surgery rates were $33.3 \%, 76.3 \%, 42.0 \%$ and $2.0 \%$ for breast, bladder, renal and lung cancer, respectively. In Cox regression analysis after propensity score matching, primary cancer surgery was associated with a significantly improved overall survival for breast [hazard ratio $(\mathrm{HR})=0.56$ ], bladder $(\mathrm{HR}=0.69)$, lung $(\mathrm{HR}=0.61)$ and renal carcinoma $(\mathrm{HR}=0.37$, while the prolonged median survival time was 20 months, 3 months, 4months and 21 months, respectively. Nomograms were constructed based on predictive factors, showing good consistency between the actual and predicted outcomes (C-index between 0.697 to 0.750 ) and feasibility in clinical practice.

Conclusions: This population-based cohort of cancer patients with bone metastasis supports primary tumor surgery as a significant protective factor for cancer patients with bone metastasis, and nomograms hold promise in assisting individualized risk stratification and accurate therapeutic strategy making.

Keywords: Bone metastasis; primary surgery; overall survival; propensity score matching; nomogram.

Submitted Jun 17, 2020. Accepted for publication Oct 16, 2020.

doi: $10.21037 /$ atm-20-4764

View this article at: http://dx.doi.org/10.21037/atm-20-4764

^ ORCID: 0000-0001-6517-7649. 


\section{Introduction}

Despite the heterogeneity across different kinds of tumor, metastasis is one of the most fatal causes of death for cancer patients. According to the US National Comprehensive Cancer Network and European guidelines (1-13), most metastatic cancer patients are not recommended to receive aggressive surgical treatment to the primary tumor, in consideration of the extent of the disease and prohibitive comorbidities. While what is the appropriate local management of the primary tumor in metastatic patients remains a common clinical scenario, mounting evidence in recent years suggest that removal of the primary malignancy offer survival benefits in some advanced stage solid tumors, including thyroid carcinoma, breast cancer, pancreatic adenocarcinoma and colorectal cancer (14-19). Furthermore, diagnostic and therapeutic advances have allowed clinicians to identify metastatic cancer patients with an improved prognosis and the potential to benefit from a more aggressive local or systemic treatment approach.

In addition, subgroup analysis suggested that patients with solitary bone metastases had significantly improved survival following complete excision of the primary tumor compared to other metastatic patterns (16,17,20-24). Bone metastases tend to cause ostealgia, pathological fracture and osteolysis, mainly reducing quality of life, but they do not result in systematic failure (e.g., cerebral hernia, liver failure or respiratory failure) which is often seen in patients with brain metastasis, liver metastasis or lung metastasis (25). This might partially account for its better prognosis and tolerance for surgical therapy. Thus, rather than ignoring the heterogeneity, determining which patients with bone metastasis can get prognostic benefit following primary malignancy surgery is a meaningful question.

The results above were found after multivariable statistical adjustment for confounding factors such as patient age, race, tumor size, histological subtype and systemic treatment among others. However, most studies are retrospective in nature with potential case selection bias, in which patients with better prognosis are more likely to undergo primary tumor surgery. The objective of this population-based investigation is to provide a comprehensive assessment of the use of surgical therapy in cancer patients with bone metastasis and primary tumors with the highest bone metastasis incidence (i.e., breast, bladder, lung, and renal carcinoma) in the National Cancer Institute's Surveillance, Epidemiology, and End Results (SEER) registry from 2010 to 2016 after minimizing a potential case selection bias by implementing stratified propensity score-matching. Reliable graphic nomograms were then constructed, which permitted individualized outcome predictions and precise risk stratification, assisting patients, clinicians, and clinical investigators during the interactive therapy modality-making process. We present the following article in accordance with the STROBE reporting checklist (available at http://dx.doi.org/10.21037/ atm-20-4764).

\section{Methods}

\section{Patients and data collection}

The SEER database is a population-based medical program including 18 cancer registries with evidence-based medicine data that cover approximately $30 \%$ of the population of the United States. We identified patients in the SEER database diagnosed with bone metastasis from January 1, 2010, through December 31, 2016 and enrolled the cancer types with highest bone metastasis incidence, i.e., bladder, breast, lung and kidney cancer. The inclusion and exclusion flow diagram is shown in Figure 1. The inclusion criteria were as follows: (I) specific cancer was identified according to International Classification of Disease for Oncology, Third Edition; (II) primary cancer was restricted as the first and only cancer diagnosis; (III) the diagnosis was confirmed by positive histology examination other than by autopsy or a death certificate; (IV) the diagnosis date was between January 1, 2010, and December 31, 2016; (V) the patients were confirmed with bone metastasis; (VI) patient age was between 20 and 80 years old. The exclusion criteria were as follows: (I) whether the patient received surgery was unknown; (II) whether the patient received radiotherapy or chemotherapy was unknown; (III) the follow-up was incomplete; (IV) the metastatic sites underwent surgery; (V) the patients were diagnosed with additional synchronous metastasis in the lung, liver or brain.

The characteristics we took into account were as follows: demographic information (year of diagnosis, patient age at diagnosis, sex, and race/ethnicity), clinical characteristics (cancer site, histology, histological grade, and tumor size), local therapy (surgery, radiotherapy, and chemotherapy), length of survival (overall survival status, cancer-specific survival status and overall survival time) and cancer-specific variables (subtype for breast cancer, sarcomatoid status for renal carcinoma, and histological subtype for lung cancer). We defined a binary indicator variable to represent any 


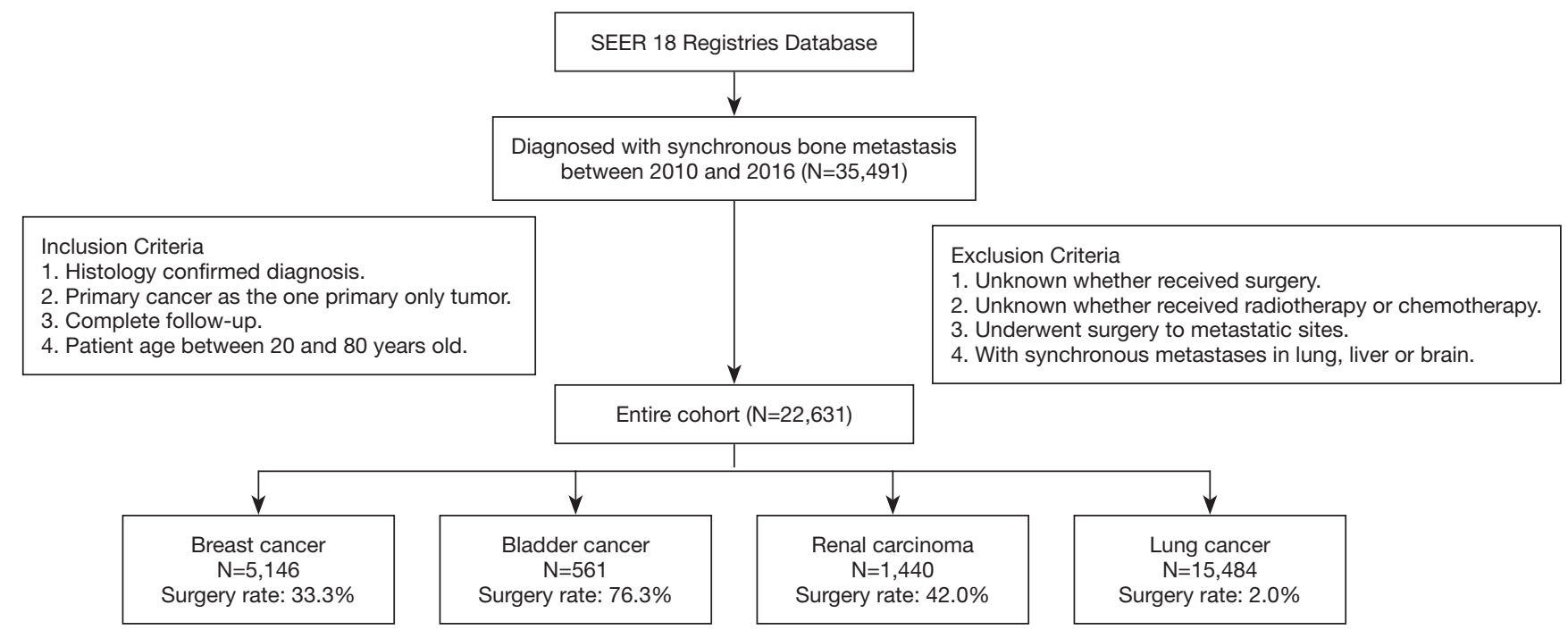

Figure 1 Flow diagram of inclusion and exclusion criteria for eligible cases. Based on the criteria, 22,631 patients were collected as the study cohort, including 5,146 breast cancer, 561 bladder cancer, 1,440 renal carcinoma and 15,484 lung cancer cases.

primary site surgery in which a specimen was sent for pathologic review (SEER site-specific surgery codes 20-90).

The study was conducted in accordance with the Declaration of Helsinki (as revised in 2013). The local institutional review board deemed studies of this nature exempt from review, so the patient consent was waived.

\section{Data preprocessing}

To avoid subjective defining of cut-off values for continuous variables, $\mathrm{X}$-tile, a bio-informatics tool for biomarker assessment and outcome-based cut-point optimization, was applied to choose optimal cut-off values for patient age and tumor size (26). Thus we transferred continuous variables into categorical variables for further analysis based on convenience and clinical consideration.

\section{Nomograms construction and evaluation}

In the study cohort, univariate prognostic factors for overall survival (OS) were determined using the Cox regression analysis, and significant factors were entered into the multivariable analysis with two-sided $\mathrm{P}$ values less than 0.05 or according to clinical consideration. With clinical relevance taken into account, the prognostic factors were integrated to construct the nomograms to predict 1 - and 3-year OS. To ensure the predictive accuracy of the nomogram, internal validation was performed $(1,000$ bootstrap resamples), whose degree of fit was assessed by calibration diagrams and the concordance index (C-index). The C-index varied from 0.5 to 1.0 , which represented random chance and a perfect fit respectively, while a C-index greater than 0.7 usually suggested a reasonable estimation. Furthermore, aiming to assess clinical usefulness of the models, decision curve analysis (DCA) was used to evaluate whether the nomogram was sufficiently robust for clinical practice. The net benefit was derived by calculating the difference between the true-positive rate and weighted false-positive rate across different threshold probabilities and was plotted against the threshold probability.

\section{Statistical analysis}

Demographic and baseline clinical characteristics were compared between surgery and non-surgery patients using $\chi^{2}$ tests for categorical variables and unpaired $t$-test for continuous variables.

The primary outcomes of this study were overall survival (OS) and cancer-specific survival (CSS). OS was defined as the total survival time from the diagnosis to death, whatever the causes, or the last date of follow-up. CSS was defined as the survival time from the diagnosis to death due to the primary cancer or the last date of follow-up. In the study cohort, univariate prognostic factors were determined using the Cox regression analysis. For clinically important variables, we defined the missing data as "unknown" to 
avoid potential bias. Significant factors were entered into the multivariable analysis with two-sided $\mathrm{P}$ values less than 0.05 or according to clinical consideration. Afterwards, we performed propensity score matching analysis, which served as a superior and more refined statistical method to adjust for potential baseline confounding variables. The "MatchIt" and the "optmatch" R packages were used to perform a bipartite weighting propensity score matching to adjust significant factors determined by the multivariate analysis $(27,28)$. We then performed subgroup analysis on patients after propensity scoring to investigate the prognostic benefits of primary malignancy surgery in different subgroups. Further nomograms were constructed and evaluated with R package "rms" and "cmprsk".

The optimal cutoff points for continuous variables were determined by X-tile software version 3.6.1 (Yale University, New Haven, CT, USA) based on 3-year OS. Most statistical analyses were performed with $\mathrm{R}$ software, version 3.5.0 (https://www.r-project.org/). All P values were two-tailed, and a $\mathrm{P}$ value $<0.05$ was considered significant.

\section{Results}

\section{Patient characteristics and treatment trend}

Our final cohort consisted of 22,631 patients (Figure 1), which we divided into two sub-cohorts for analysis based on whether patients received surgery. The surgery rates were $33.3 \%, 76.3 \%, 42.0 \%$ and $2.0 \%$ for breast $(\mathrm{N}=5,146)$, bladder $(\mathrm{N}=561)$, lung $(\mathrm{N}=1,440)$ and renal carcinoma $(\mathrm{N}=15,484)$, respectively. The average follow-up time was 25.7, 8.4, 8.4 and 16.0 months respectively, some of which was very short due to the poor prognosis of metastatic cancer. Summary statistics for the demographics and clinicopathologic variables of patients treated with and without primary tumor surgery are shown in Table 1 and Tables S1-S3. Using X-tile software, we identified the optimal cutoff points for continuous variables such as patient age and tumor size (Figure S1), based on which these characteristics were stratified into 2 or 3 categories for clinical convenience in the subsequent analysis.

In the raw cohort, primary tumor surgery rates varied considerably over several demographic variables including sex, race and age. There was also a difference when patients were analyzed using tumor characteristics, where patients treated with surgery seemed to be with younger age, smaller tumor size, lower histological grade and less additional metastasis. Patients who received surgery also more often received radiation and/or chemotherapy as part of their systematic treatment. These findings highlighted that there were notable patient-specific differences and patient selection bias between surgery and non-surgery groups, which should be taken into account when analyzing the prognostic benefit of surgery.

For surgical trends, we examined the primary malignancy surgical management through 2010 and 2016 for individual cancer. Figure S2 displays the trends for the rate of primary cancer removal over time. The rate of breast cancer patients undergoing a primary cancer surgery has decreased from $42.1 \%$ in 2010 to $26.0 \%$ in $2016(\mathrm{P}<0.001)$ while the similar tendency was observed in other cancer types. Of the four cancer types, lung cancer patients held the lowest surgical rate, remaining steadily at around $2 \%$.

\section{Primary tumor surgery as a prognostic factor for survival}

Univariate analysis was carried out to identify patient characteristics correlated with OS. Overall, the log-rank univariate test identified patient age at diagnosis, sex, race, tumor size, histological grade, histological subtype and therapy (surgery, radiotherapy and chemotherapy) as being associated with OS (Table 2 for breast cancer and Tables S4-S6 for the other cancer types). These variables were included in the multivariate Cox regression analysis and the confirmed independent prognostic factors associated with OS are also shown in Table 2 and Tables S4-S6. These results revealed independent impact of primary surgery on OS in breast cancer (HR $=0.58,95 \%$ CI: $0.52-0.65$ ), bladder cancer $(\mathrm{HR}=0.64,95 \% \mathrm{CI}$ : 0.51-0.80), lung cancer (HR $=0.55,95 \%$ CI: $0.48-0.63)$ and renal carcinoma (HR $=0.34,95 \%$ CI: 0.27-0.41).

\section{Adjusting for patients characteristics with propensity score matching}

In the analysis above, we found primary tumor surgery rates varied considerably over several demographic variables, clinicopathologic characteristics and therapy strategies. To further corroborate the findings from univariate and multivariable Cox proportional hazard regression analyses, a propensity score matching was performed to optimally adjust for the aforementioned significant variables identified in the multivariable Cox regression analysis, in order to reduce potential patient selection bias between the two groups. After propensity score matching in the "nearest" method with ratio $=1$, we obtained as many 
Table 1 Patient and tumor characteristics of breast cancer patients grouped by surgery before and after propensity score matching $(\mathrm{N}=5,146)$

\begin{tabular}{|c|c|c|c|c|c|}
\hline Characteristics & \multicolumn{3}{|c|}{ Pre-matching } & \multicolumn{2}{|c|}{ Post-Matching } \\
\hline Age, years & & & $<0.001^{*}$ & & $0.008^{*}$ \\
\hline$<50$ & $688(20.0)$ & $530(30.9)$ & & $448(26.1)$ & \\
\hline $50-70$ & $2,082(60.7)$ & 955 (55.7) & & $1,018(59.4)$ & \\
\hline Race & & & 0.482 & & 0.355 \\
\hline Black & $527(15.4)$ & 266 (15.5) & & $266(15.5)$ & \\
\hline White & 2,658 (77.4) & 1,309 (76.4) & & 1,331 (77.7) & \\
\hline Other & $247(7.2)$ & $139(8.1)$ & & $117(6.8)$ & \\
\hline II & 1,355 (39.5) & 704 (41.1) & & 766 (44.7) & \\
\hline III & 889 (25.9) & 765 (44.6) & & $686(40.0)$ & \\
\hline IV & $12(0.3)$ & $5(0.3)$ & & $5(0.3)$ & \\
\hline Unknown & $859(25.0)$ & $111(6.5)$ & & $107(6.2)$ & \\
\hline Tumor size & & & $<0.001^{*}$ & & 0.879 \\
\hline$<8 \mathrm{~cm}$ & 2,448 (71.3) & $1,414(82.5)$ & & 1,425 (83.1) & \\
\hline$>8 \mathrm{~cm}$ & $258(7.5)$ & $185(10.8)$ & & 177 (10.3) & \\
\hline Unknown & $726(21.2)$ & $115(6.7)$ & & $112(6.5)$ & \\
\hline Radiation & & & $<0.001^{*}$ & & $<0.001^{*}$ \\
\hline No & 3,165 (92.2) & 806 (47.0) & & 1,584 (92.4) & \\
\hline Yes & $267(7.8)$ & 908 (53.0) & & $130(7.6)$ & \\
\hline Chemotherapy & & & $<0.001^{\star}$ & & 0.401 \\
\hline No & $1,825(53.2)$ & $540(31.5)$ & & $564(32.9)$ & \\
\hline Yes & 1,607 (46.8) & $1,174(68.5)$ & & $1,150(67.1)$ & \\
\hline
\end{tabular}

Values are expressed as $\mathrm{n}(\%)$ unless otherwise indicated. *, Two-sided $\mathrm{P}$ values $<0.05$.

patients without surgery as patients with surgery. Figure S3 displays the distribution of the propensity scores of the two groups prior to and after propensity score matching and weighting. Table 1 and Tables S1-S3 summarize patient characteristics after propensity score weighting. As is shown in the tables, most baseline information between the two groups are balanced without significant differences $\left(\mathrm{P}>0.05\right.$ in $\chi^{2}$ tests $)$. 
Page 6 of 13

Wu et al. Primary surgery benefits patients with bone metastasis

Table 2 Prognostic factors for overall survival in breast cancer patients $(\mathrm{N}=5,146)$

\begin{tabular}{|c|c|c|c|c|}
\hline Characteristics & \multicolumn{2}{|c|}{ Univariate } & \multicolumn{2}{|c|}{ Multivariate } \\
\hline \multicolumn{5}{|l|}{ Age, years } \\
\hline$<50$ & Reference & & Reference & \\
\hline $50-70$ & $1.64(1.47-1.83)$ & $<0.001^{*}$ & $1.49(1.34-1.67)$ & $<0.001^{*}$ \\
\hline \multicolumn{5}{|l|}{ Race } \\
\hline Black & Reference & & Reference & \\
\hline White & $0.71(0.64-0.79)$ & $<0.001^{*}$ & $0.77(0.69-0.86)$ & $<0.001^{\star}$ \\
\hline Other & $0.64(0.53-0.77)$ & $<0.001^{*}$ & $0.75(0.62-0.91)$ & $0.003^{*}$ \\
\hline$>8 \mathrm{~cm}$ & $1.43(1.24-1.64)$ & $<0.001^{*}$ & $1.43(1.24-1.65)$ & $<0.001^{\star}$ \\
\hline Unknown & $1.6(1.44-1.77)$ & $<0.001^{*}$ & $1.46(1.31-1.63)$ & $<0.001^{\star}$ \\
\hline \multicolumn{5}{|l|}{ Grade } \\
\hline 1 & Reference & & Reference & \\
\hline II & $1.03(0.87-1.21)$ & 0.769 & $1.14(0.96-1.35)$ & 0.134 \\
\hline III & $1.42(1.2-1.68)$ & $<0.001^{*}$ & $1.63(1.37-1.94)$ & $<0.001^{*}$ \\
\hline IV & $2.61(1.48-4.59)$ & $0.001^{*}$ & $2.48(1.4-4.38)$ & $0.002^{*}$ \\
\hline Unknown & $1.41(1.18-1.68)$ & $<0.001^{*}$ & $1.15(0.96-1.38)$ & 0.124 \\
\hline \multicolumn{5}{|l|}{ Subtype } \\
\hline \multicolumn{5}{|l|}{ Surgery } \\
\hline No & Reference & & Reference & \\
\hline Yes & $0.54(0.49-0.59)$ & $<0.001^{*}$ & $0.58(0.52-0.65)$ & $<0.001^{*}$ \\
\hline \multicolumn{5}{|l|}{ Radiation } \\
\hline No & Reference & & Reference & \\
\hline Yes & $0.63(0.57-0.7)$ & $<0.001^{*}$ & $0.91(0.81-1.03)$ & 0.129 \\
\hline \multicolumn{5}{|l|}{ Chemotherapy } \\
\hline No & Reference & & Reference & \\
\hline Yes & $0.66(0.61-0.72)$ & $<0.001^{\star}$ & $0.7(0.64-0.77)$ & $<0.001^{\star}$ \\
\hline
\end{tabular}

Values are expressed as hazard ratios (HR) with $95 \%$ confidence intervals unless otherwise indicated. *, Two-sided $\mathrm{P}$ values $<0.05$. 
A

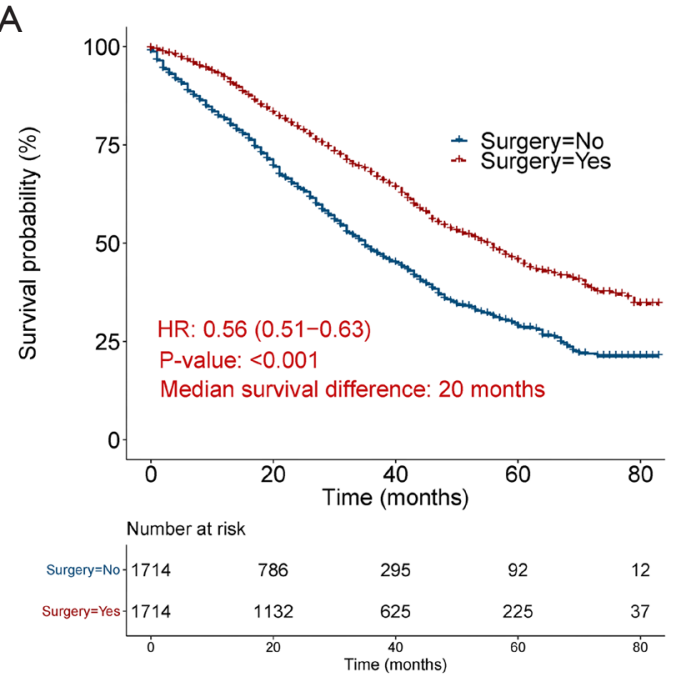

C
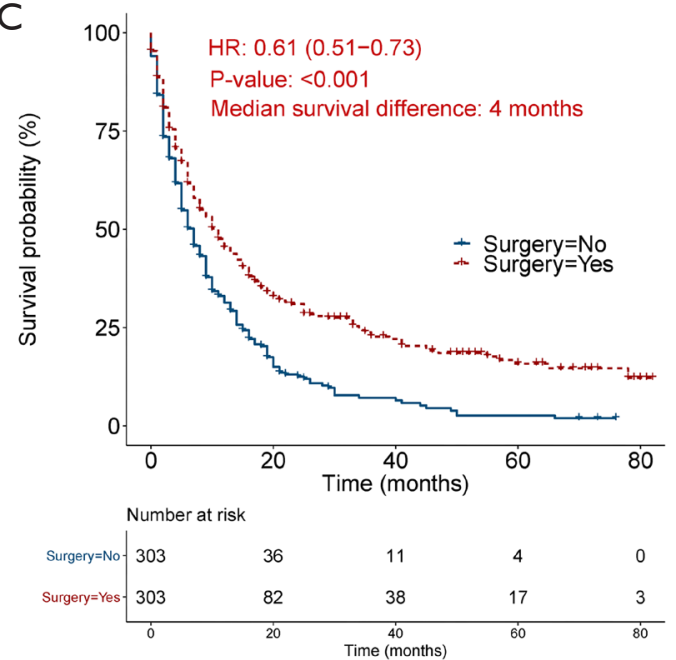
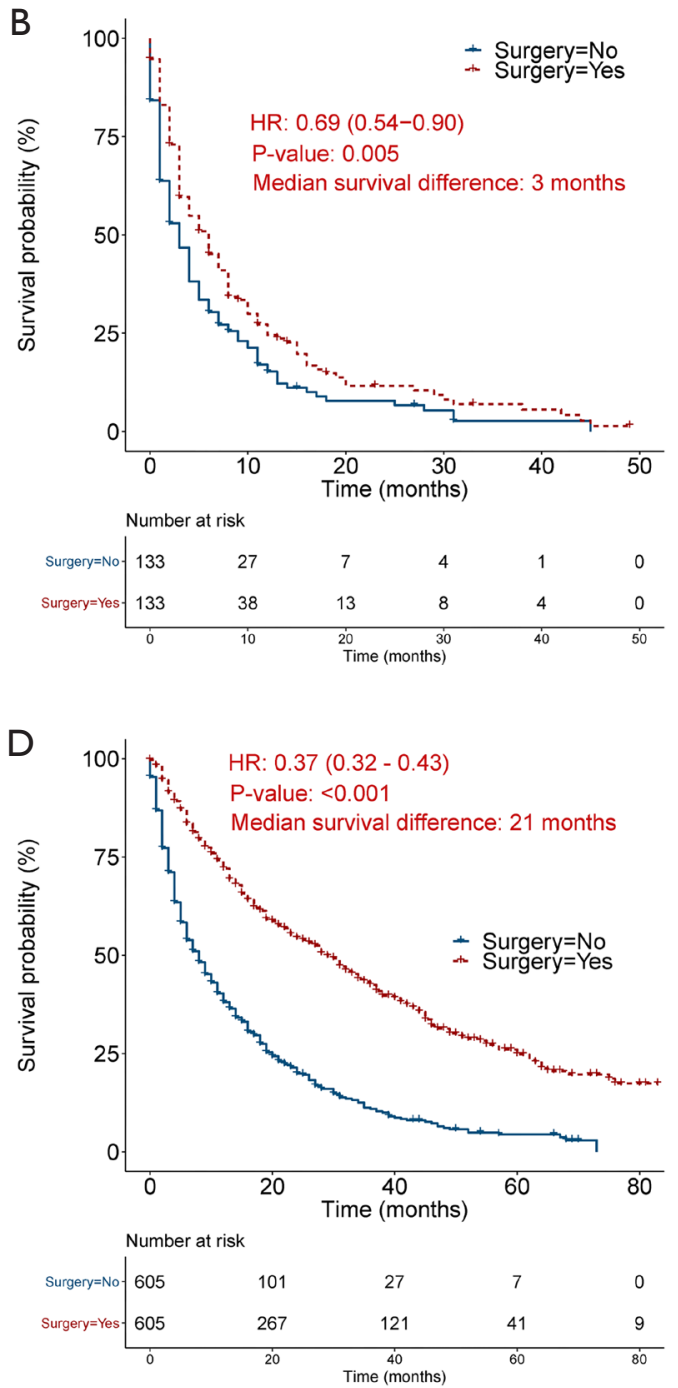

Figure 2 Kaplan-Meier curve showing overall survival by primary tumor surgery after propensity score matching. (A), (B), (C), and (D) represents breast cancer, bladder cancer, lung cancer, and renal carcinoma, respectively.

\section{Propensity-score-matched prognostic factors for long-term survival}

After propensity score matching, the Cox regression analysis and Kaplan-Meier survival analysis (Figure 2) demonstrated that primary tumor surgery persisted to be a significant protective predictor for OS in breast cancer ( $\mathrm{HR}=0.56,95 \%$ CI: 0.51-0.63), bladder cancer $(\mathrm{HR}=0.69$, 95\% CI: 0.54-0.90), lung cancer (HR $=0.61,95 \%$ CI: 0.51 0.73 ) and renal carcinoma (HR $=0.37,95 \%$ CI: $0.32-0.43$ ). To diminish the effects of other death causes on patients' survival, we also compared CSS between surgery group and non-surgery group and found that primary malignancy surgery was still a significant prognostic factor in breast cancer (HR $=0.56,95 \%$ CI: 0.50-0.63), bladder cancer (HR $=0.67,95 \%$ CI: $0.52-0.88)$, lung cancer $(\mathrm{HR}=0.59,95 \%$ CI: $0.49-0.71)$ and renal carcinoma (HR $=0.36,95 \%$ CI: 0.31-0.42) (Figure S4).

Finally, we evaluated the prognostic role of surgery in demographic and clinicopathologic subgroups. Although the results of subgroup analysis were heterogeneous, surgery was supported as a favorable prognostic trait in most subgroups (Figure 3) especially in breast cancer, renal carcinoma and lung cancer. 
A

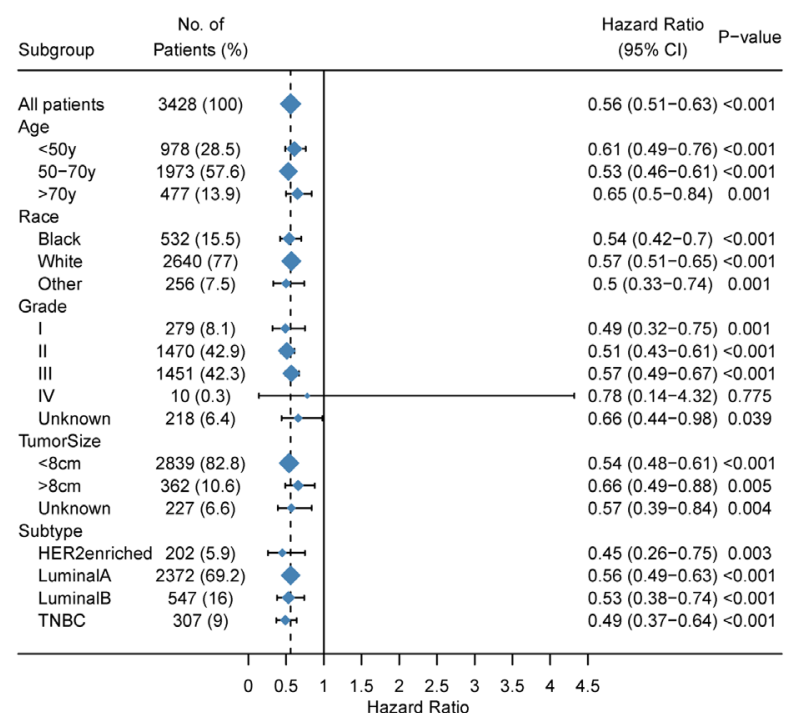

C

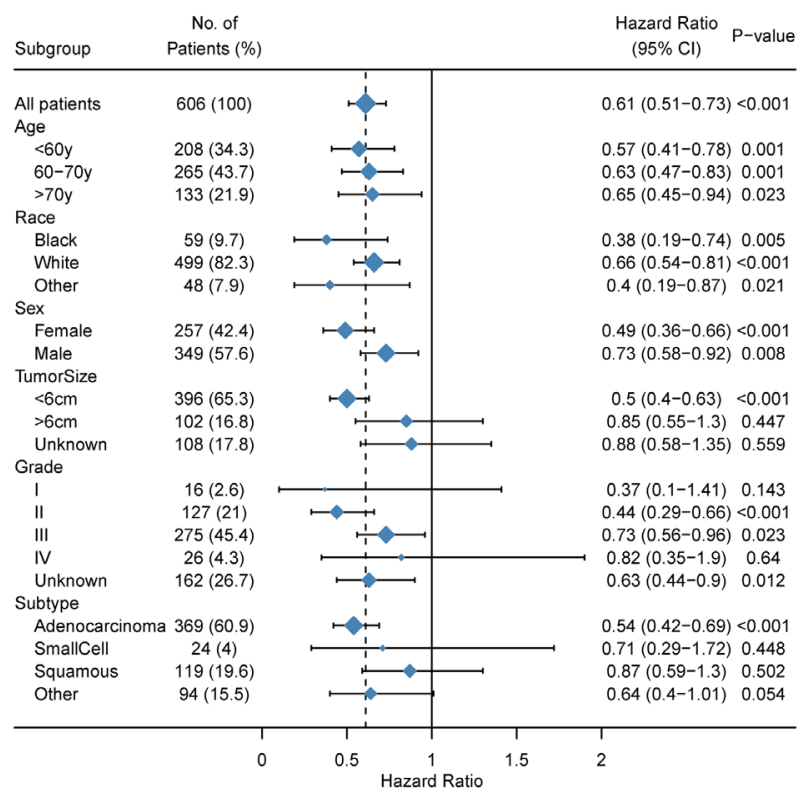

B

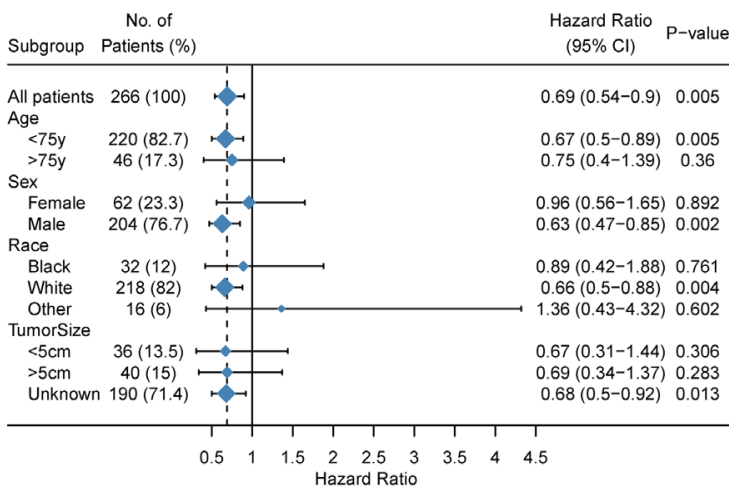

D

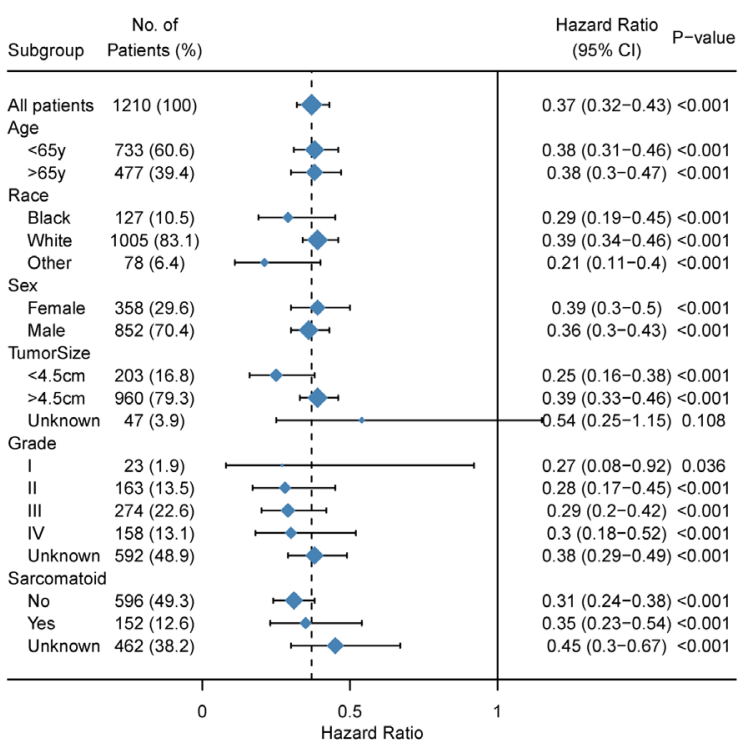

Figure 3 Subgroup analyses estimating prognostic value of primary tumor surgery grouped by different demographics and clinicopathologic characteristics. Hazard ratio (HR) $<1.0$ indicates that surgery is a favorable prognostic factor. (A), (B), (C), and (D) represents breast cancer, bladder cancer, lung cancer, and renal carcinoma, respectively.

\section{Reliable nomograms predict 1- and 3-year OS}

Only variables that were significantly associated with OS $(\mathrm{P}<0.05$, Table 2 and Tables S4-S6) were included in the construction of nomograms to predict the 1- and 3-year survival status (Figure 4). In these nomograms, primary tumor surgery contributed the most in renal carcinoma patients while it contributed moderately in breast cancer, bladder cancer and lung cancer patients. The C-indexes were 0.697 (95\% CI: 0.691-0.703), 0.750 (95\% CI: 0.734-0.767), 0.716 (95\% CI: 0.714-0.719), 0.704 (95\% CI: 0.696-0.713) for breast cancer, bladder cancer, lung cancer and renal carcinoma, respectively, demonstrating a reasonable estimation. The calibration plot diagrams showed an optimal agreement between the prediction by nomogram and actual observation for the 1- and 3-year 
A

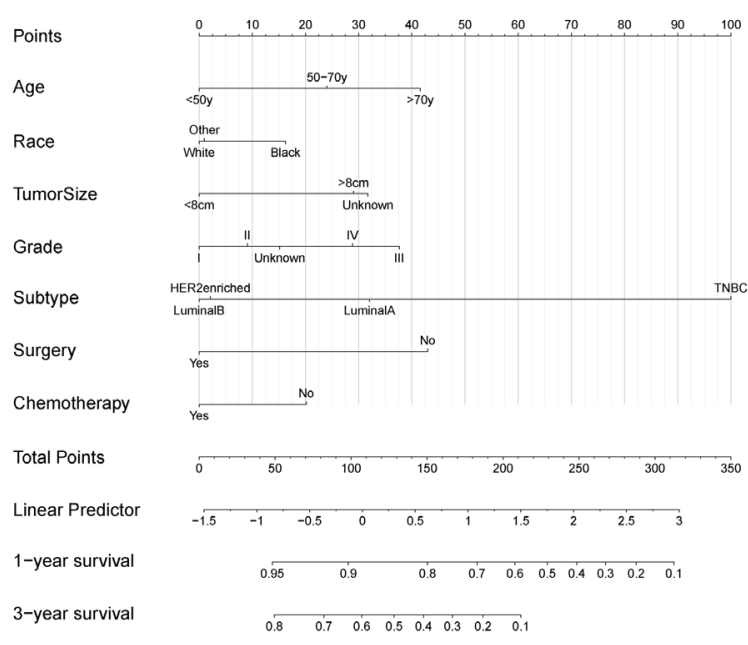

C

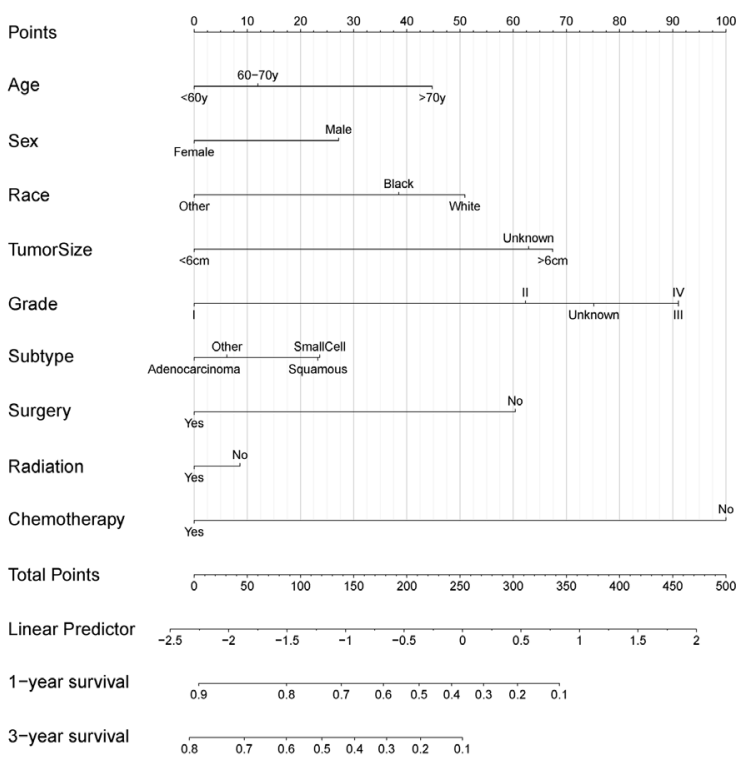

B

Age

TumorSize

Surgery

Chemotherapy

Total Points

Linear Predictor

1-year survival

3-year survival
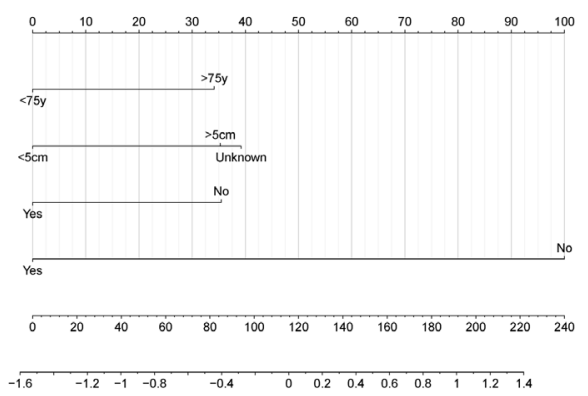

$$
\begin{array}{llllll}
0.6 & 0.5 & 0.4 & 0.3 & 0.2 & 0.1
\end{array}
$$

$\begin{array}{llll}0.4 & 0.3 & 0.2 & 0.1\end{array}$
D

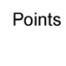

Age

Sarcomatoid

Surgery

Chemotherapy

Total Points

Linear Predictor

1-year survival

3-year survival
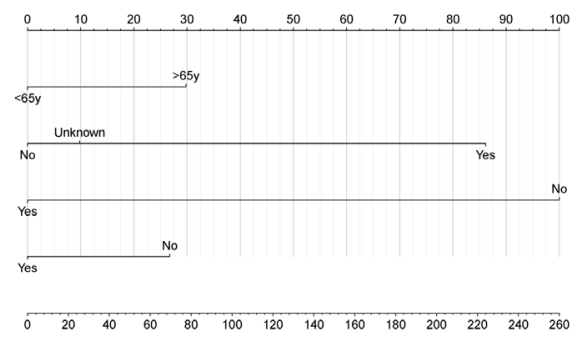

$\begin{array}{llllllllllllllll}-1 & -0.8 & -0.6 & -0.4 & -0.2 & 0 & 0.2 & 0.4 & 0.6 & 0.8 & 1 & 1.2 & 1.4 & 1.6 & 1.8\end{array}$

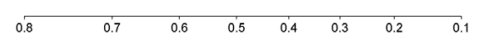

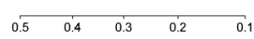

Figure 4 Nomograms for predicting the 1- and 3-year overall survival rate for breast cancer (A), bladder cancer (B), lung cancer (C), and renal carcinoma (D) patients with synchronous solitary bone metastasis.

OS (Figure S5). DCA curves showed that our nomogram gained more net benefits than the treat-all-patients strategy, the treat-none-patient strategy and surgery-only strategy, suggesting that the nomogram we developed was sufficiently robust for clinical practice (Figure S6).

\section{Discussion}

While whether aggressive surgical management should be conducted to the primary tumor in metastatic patients remains a heated debate, mounting evidence in recent years suggest that removal of the primary tumor offer survival benefit in some advanced stage tumors, including thyroid carcinoma, breast cancer, pancreatic adenocarcinoma and colorectal cancer $(14,15,17,19)$. Furthermore, these studies revealed that patients with synchronous bone metastasis had relative better prognosis and could benefit from primary tumor surgery compared to other metastatic patterns. The 
intrinsic reason for the differences remains to be clarified, but some studies proposed that it might be because the biological property of bone metastases caused less systematic failures $(25,29-31)$. Thus patients could survive with better physical condition and tolerate surgical therapy with the subsequent potential complications. In conclusion, bone metastasis might be a special metastatic pattern with distinct characteristics. As the first population-based bone-metastasis-focused analysis, we sought to investigate whether primary tumor surgery could prolong the survival of patients with bone metastasis and primary breast cancer, bladder cancer, lung cancer and renal carcinoma, which are the most prone to develop bone metastasis.

With confounding factors adjusted in the propensity score matching analysis between patients with or without primary surgery, we found renal carcinoma patients could benefit from primary malignancy surgery with the most reduced relative risk $(\mathrm{HR}=0.37, \mathrm{P}<0.001)$ while it also appeared as a significant protective factor for breast cancer $(\mathrm{HR}=0.56, \mathrm{P}<0.001)$, bladder cancer $(\mathrm{HR}$ $=0.69, \mathrm{P}=0.005)$ and lung cancer $(\mathrm{HR}=0.61, \mathrm{P}<0.001)$ patients. These results were in general in accordance with the previous researches and preliminary results of several RCT (randomized controlled trial) $(20,32,33)$. In line with expectations, subgroup analysis revealed that best surgical benefits were obtained in patients with younger age, smaller tumor size and lower histological grade, despite the heterogeneities across different cancer types. Furthermore, we also discovered that HER2positive (human epidermal growth factor receptor-2) breast cancer, non-sarcomatoid renal carcinoma and lung adenocarcinoma were the corresponding histological subtype with the best surgical benefits. The results above provided references for clinicians and patients on deciding whether or not receiving primary surgery based on individual characteristics. The results enhanced the credibility of the hypothesis that bone metastases caused less systematic burden, with which patients could have had more chances to receive aggressive local surgical treatment to the primary tumor and get better prognosis benefits. In spite of the strictly restricted patient group and long period of recruiting and follow-up, the number of ongoing RCTs assessing the impact of loco-regional treatment on survival in metastatic cancer patients emphasize the cardinal importance of the clinical problem.

Given the clear relationship with improved survival, it is surprising that local surgical treatment rates have been extremely low in lung cancer patients and the rates have decreased annually, especially in breast cancer (from $42.1 \%$ in 2010 to $26.0 \%$ in 2016). However, despite the presence of statistic difference, we found the absolute median survival time benefits were 20 months, 3 months, 4 months and 21 months for breast cancer, bladder cancer, lung cancer and renal carcinoma, respectively. Since the prolonged median survival time was just 4 months for lung cancer patients, it is reasonable that their primary tumor surgical rate remained as low as $2 \%$ with physical status, postoperative management and economic burden taken into account. It is worth mentioning that the prolonged median overall survival was just 3 months for bladder cancer patients, but the surgical rate remained extremely high in recent years $(>50 \%)$. Prognostic benefits should be considered when determining whether patients could receive surgical treatment.

From these data, it is tempting to draw a conclusion that surgery is underutilized for patients with bone metastasis which might result in less systematic burden than other visceral metastases. In most of the current clinical guidelines and clinical practices, metastatic cancer patients were simply graded as TNM stage M1 and American Joint Committee on Cancer (AJCC) stage IV with the same treatment strategy while they were not subdivided according to the metastatic patterns. This grading ignored the metastatic heterogeneity and might prevent some patients from potentially curative surgical management, at least in patients with bone metastasis as revealed above. The dogma that metastatic cancer patients are only recommended with palliative surgery or without surgery should be questioned. However on the other hand, the advanced age, prohibitive comorbidities, operating difficulty, postoperative care and economic conditions should also be taken into account when making therapy strategy.

Nomograms are being increasingly accepted as predictive models in which known prognostic factors can be integrated with specific weight and used for risk prediction in cancer (34). In the present study, we constructed nomograms for predicting 1 - and 3-year overall survival probability for patients with bone metastasis, with which personalized surgical benefits can be estimated before treatment. As for the efficacy, these nomograms predicted OS with C-index between 0.697 to 0.750 , demonstrating that the models were reliable with great consistency and discrimination. In addition, DCA curves revealed great performance of our nomograms in net benefit in predicting survival for these patients, signifying the sufficient robustness for clinical practice. In conclusion, these nomograms act as convenient 
and feasible models for clinicians and even patients themselves.

We would like to acknowledge the limitations of this study. The main drawback of this analysis is the lack of information on detailed chemotherapeutic drugs or targeted therapy used as well as the time from diagnosis to treatment, which are essential parts of multidisciplinary approach and have important impact on patients' prognosis $(35,36)$. Similarly, comorbidities and general conditions are also not available in the SEER registry, which are important considerations for patient selection for surgery. Although we performed propensity score matching analysis to reduce relevant selection bias, this adjustment was only possible for known confounders enrolled in the SEER data set while the remaining confounding variables might impact the interpretation of the data, to which extent remains unclear. Secondly, since the cohort was extracted from the United States population, the generalizability of our results to other countries is limited as health care financing systems and clinical practices vary across different countries.

In conclusion, as the first population-based bonemetastasis-focused analysis, our study supports the favorable impact of primary malignancy surgery on clinical outcomes in breast cancer, bladder cancer, lung cancer and renal carcinoma patients with synchronous solitary bone metastasis. The dogma that cancer patients with bone metastasis are only recommended with palliative surgery or without surgery should be questioned. Furthermore, we devised pretreatment nomograms to predict overall survival probabilities with high level of validation and accuracy. These findings are recommended to be provided to physicians and patients so that they can properly weigh the risks and benefits of aggressive local surgical management and make interactive therapy decisions.

\section{Acknowledgments}

The authors would like to thank SEER for open access to the database.

Funding: This work was supported by funds from the National Key R\&D program of China (No. 2016YFB1101305 to FL) and the National Natural Science Foundation of China (No. 81874024 to FL).

\section{Footnote}

Reporting Checklist: The authors have completed the STROBE reporting checklist. Available at http://dx.doi. org/10.21037/atm-20-4764

Conflicts of Interest: All authors have completed the ICMJE uniform disclosure form (available at http://dx.doi. org/10.21037/atm-20-4764). The authors have no conflicts of interest to declare.

Etbical Statement: The authors are accountable for all aspects of the work in ensuring that questions related to the accuracy or integrity of any part of the work are appropriately investigated and resolved. The study was conducted in accordance with the Declaration of Helsinki (as revised in 2013).

Open Access Statement: This is an Open Access article distributed in accordance with the Creative Commons Attribution-NonCommercial-NoDerivs 4.0 International License (CC BY-NC-ND 4.0), which permits the noncommercial replication and distribution of the article with the strict proviso that no changes or edits are made and the original work is properly cited (including links to both the formal publication through the relevant DOI and the license). See: https://creativecommons.org/licenses/by-nc-nd/4.0/.

\section{References}

1. Kalemkerian GP, Akerley W, Bogner P, et al. Small cell lung cancer. J Natl Compr Canc Netw 2013;11:78-98.

2. Ettinger DS, Wood DE, Aisner DL, et al. Non-Small Cell Lung Cancer, Version 5.2017, NCCN Clinical Practice Guidelines in Oncology. J Natl Compr Canc Netw 2017;15:504-35.

3. Escudier B, Kataja V, Group EGW. Renal cell carcinoma: ESMO Clinical Practice Guidelines for diagnosis, treatment and follow-up. Ann Oncol 2010;21 Suppl 5:v137-9.

4. Telli ML, Gradishar WJ, Ward JH. NCCN Guidelines Updates: Breast Cancer. J Natl Compr Canc Netw 2019;17:552-5.

5. Flaig TW, Spiess PE, Agarwal N, et al. NCCN Guidelines Insights: Bladder Cancer, Version 5.2018. J Natl Compr Canc Netw 2018;16:1041-53.

6. Goetz MP, Gradishar WJ, Anderson BO, et al. NCCN Guidelines Insights: Breast Cancer, Version 3.2018. J Natl Compr Canc Netw 2019;17:118-26.

7. D'Addario G, Fruh M, Reck M, et al. Metastatic nonsmall-cell lung cancer: ESMO Clinical Practice Guidelines for diagnosis, treatment and follow-up. Ann Oncol 
2010;21 Suppl 5:v116-9.

8. Cardoso F, Harbeck N, Fallowfield L, et al. Locally recurrent or metastatic breast cancer: ESMO Clinical Practice Guidelines for diagnosis, treatment and followup. Ann Oncol 2012;23 Suppl 7:vii11-9.

9. Motzer RJ, Jonasch E, Agarwal N, et al. Kidney Cancer, Version 2.2017, NCCN Clinical Practice Guidelines in Oncology. J Natl Compr Canc Netw 2017;15:804-34.

10. Gradishar WJ, Anderson BO, Balassanian R, et al. Breast Cancer, Version 4.2017, NCCN Clinical Practice Guidelines in Oncology. J Natl Compr Canc Netw 2018;16:310-20.

11. Coleman R, Body JJ, Aapro M, et al. Bone health in cancer patients: ESMO Clinical Practice Guidelines. Ann Oncol 2014;25 Suppl 3:iii124-37.

12. Bellmunt J, Orsola A, Maldonado X, et al. Bladder cancer: ESMO Practice Guidelines for diagnosis, treatment and follow-up. Ann Oncol 2010;21 Suppl 5:v134-6.

13. Spiess PE, Agarwal N, Bangs R, et al. Bladder Cancer, Version 5.2017, NCCN Clinical Practice Guidelines in Oncology. J Natl Compr Canc Netw 2017;15:1240-67.

14. Tarantino I, Warschkow R, Worni M, et al. Prognostic Relevance of Palliative Primary Tumor Removal in 37,793 Metastatic Colorectal Cancer Patients: A PopulationBased, Propensity Score-Adjusted Trend Analysis. Ann Surg 2015;262:112-20.

15. McDowell BD, Chapman CG, Smith BJ, et al. Pancreatectomy predicts improved survival for pancreatic adenocarcinoma: results of an instrumental variable analysis. Ann Surg 2015;261:740-5.

16. Wang K, Shi Y, Li ZY, et al. Metastatic pattern discriminates survival benefit of primary surgery for de novo stage IV breast cancer: A real-world observational study. Eur J Surg Oncol 2019;45:1364-72.

17. Thomas A, Khan SA, Chrischilles EA, et al. Initial Surgery and Survival in Stage IV Breast Cancer in the United States, 1988-2011. JAMA Surg 2016;151:424-31.

18. Warschkow R, Guller U, Tarantino I, et al. Improved Survival After Primary Tumor Surgery in Metastatic Breast Cancer: A Propensity-adjusted, Population-based SEER Trend Analysis. Ann Surg 2016;263:1188-98.

19. Lee J, Soh EY. Differentiated thyroid carcinoma presenting with distant metastasis at initial diagnosis clinical outcomes and prognostic factors. Ann Surg 2010;251:114-9.

20. Soran A, Ozmen V, Ozbas S, et al. Randomized Trial Comparing Resection of Primary Tumor with No Surgery in Stage IV Breast Cancer at Presentation: Protocol MF07-01. Ann Surg Oncol 2018;25:3141-9.
21. Yong M, Jensen AO, Jacobsen JB, et al. Survival in breast cancer patients with bone metastases and skeletal-related events: a population-based cohort study in Denmark (1999-2007). Breast Cancer Res Treat 2011;129:495-503.

22. Gong Y, Liu YR, Ji P, et al. Impact of molecular subtypes on metastatic breast cancer patients: a SEER populationbased study. Sci Rep 2017;7:45411.

23. Xiong Z, Deng G, Huang X, et al. Bone metastasis pattern in initial metastatic breast cancer: a population-based study. Cancer Manag Res 2018;10:287-95.

24. Zhang C, Liu L, Tao F, et al. Bone Metastases Pattern in Newly Diagnosed Metastatic Bladder Cancer: A Population-Based Study. J Cancer 2018;9:4706-11.

25. Logothetis CJ, Navone NM, Lin SH. Understanding the biology of bone metastases: key to the effective treatment of prostate cancer. Clin Cancer Res 2008;14:1599-602.

26. Camp RL, Dolled-Filhart M, Rimm DL. X-tile: a new bio-informatics tool for biomarker assessment and outcome-based cut-point optimization. Clin Cancer Res 2004;10:7252-9.

27. Ho DE, Imai K, King G, et al. MatchIt: Nonparametric Preprocessing for Parametric Causal Inference. Journal of Statistical Software 2011;42:28.

28. Hansen BB, Klopfer SO. Optimal Full Matching and Related Designs via Network Flows. Journal of Computational and Graphical Statistics 2006;15:609-27.

29. Gdowski AS, Ranjan A, Vishwanatha JK. Current concepts in bone metastasis, contemporary therapeutic strategies and ongoing clinical trials. J Exp Clin Cancer Res 2017;36:108.

30. Hassanshahi M, Hassanshahi A, Khabbazi S, et al. Bone marrow sinusoidal endothelium: damage and potential regeneration following cancer radiotherapy or chemotherapy. Angiogenesis 2017;20:427-42.

31. Salvador F, Llorente A, Gomis RR. From latency to overt bone metastasis in breast cancer: potential for treatment and prevention. J Pathol 2019;249:6-18.

32. Badwe R, Hawaldar R, Nair N, et al. Locoregional treatment versus no treatment of the primary tumour in metastatic breast cancer: an open-label randomised controlled trial. Lancet Oncol 2015;16:1380-8.

33. Xiao W, Zou Y, Zheng S, et al. Primary tumor resection in stage IV breast cancer: A systematic review and metaanalysis. Eur J Surg Oncol 2018;44:1504-12.

34. Balachandran VP, Gonen M, Smith JJ, et al. Nomograms 
in oncology: more than meets the eye. Lancet Oncol 2015;16:e173-80.

35. Bedard PL, Hyman DM, Davids MS, et al. Small molecules, big impact: 20 years of targeted therapy in oncology. Lancet 2020;395:1078-88.

36. Kurzrock R, Kantarjian HM, Kesselheim AS, et al. New drug approvals in oncology. Nat Rev Clin Oncol 2020;17:140-6.
Cite this article as: $\mathrm{Wu} \mathrm{W,} \mathrm{Zhang} \mathrm{H,} \mathrm{Fang} \mathrm{Z,} \mathrm{Li} \mathrm{F.} \mathrm{Primary}$ tumor surgery improves survival of cancer patients with synchronous solitary bone metastasis: a large population-based study. Ann Transl Med 2021;9(1):31. doi: 10.21037/atm-20-4764 
Figure S1 The optimal cut-off of patient age and tumor size for patients based on X-tile software. The histograms showed distribution of patients while Kaplan-Meier plot showed overall survival in groups stratified using the optimal cutoff value, where turquois, grey and purple represents low-, middle- and high-level respectively. (A), (B), (C), and (D) represents breast cancer, bladder cancer, lung cancer, and renal carcinoma, respectively. 
Figure S2 Receipt of surgical therapy over time in individual cancer type. The bar width is proportional to the number of cases. (A), (B), (C), and (D) represents breast cancer, bladder cancer, lung cancer, and renal carcinoma, respectively. 
Figure S3 Distribution of propensity score before and after propensity matching procedure. (A), (B), (C) and (D) represents breast cancer, bladder cancer, lung cancer, and renal carcinoma, respectively. 
Figure S4 Kaplan-Meier curve showing cancer-specific survival by primary tumor surgery after propensity score matching. (A), (B), (C), and (D) represents breast cancer, bladder cancer, lung cancer, and renal carcinoma, respectively. 
Figure S5 Calibration curve for predicting patient survival at 1- and 3-year overall survival. X-axis is nomogram-predicted survival probability, and y-axis is actual survival probability. Dashed line indicates the reference line on which an ideal nomogram would lie. (A), (B), (C), and (D) represents breast cancer, bladder cancer, lung cancer, and renal carcinoma, respectively. 
Figure S6 Net decision curve analyses demonstrate the comparison of benefit for predicting survival for overall survival. The y-axis indicates the net benefit, and $\mathrm{x}$-axis indicates threshold probability. The blue line represents net benefit of the nomogram; red line represents net benefit of surgery-only; green line represents the hypothesis that all patients die within 3 years; black line represents the hypothesis that no patient dies within 3 years. (A), (B), (C), and (D) represents breast cancer, bladder cancer, lung cancer, and renal carcinoma, respectively. 
Table S1 Patient and tumor characteristics of bladder cancer patients grouped by surgery before and after propensity score matching (N=561)

\begin{tabular}{|c|c|c|c|c|c|}
\hline \multirow{2}{*}{ Characteristics } & \multicolumn{3}{|c|}{ Pre-Matching } & \multicolumn{2}{|c|}{ Post-Matching } \\
\hline & $N=133$ & $\mathrm{~N}=428$ & $\mathrm{P}$ & $N=133$ & $\mathrm{P}$ \\
\hline Age & & & 0.596 & & 1 \\
\hline$<75 y$ & $110(82.7 \%)$ & $343(80.1 \%)$ & & $110(82.7 \%)$ & \\
\hline Race & & & 0.896 & & 0.829 \\
\hline Black & $17(12.8 \%)$ & 49 (11.4\%) & & $15(11.3 \%)$ & \\
\hline White & $109(82 \%)$ & $354(82.7 \%)$ & & $109(82 \%)$ & \\
\hline Other & 7 (5.3\%) & $25(5.8 \%)$ & & $9(6.8 \%)$ & \\
\hline Male & $102(76.7 \%)$ & 335 (78.3\%) & & $102(76.7 \%)$ & \\
\hline Grade & & & $<0.001^{\star}$ & & $<0.001^{*}$ \\
\hline I & $0(0 \%)$ & $5(1.2 \%)$ & & $3(2.3 \%)$ & \\
\hline ॥ & $3(2.3 \%)$ & $12(2.8 \%)$ & & 5 (3.8\%) & \\
\hline III & 26 (19.5\%) & $88(20.6 \%)$ & & 25 (18.8\%) & \\
\hline IV & $41(30.8 \%)$ & 265 (61.9\%) & & 85 (63.9\%) & \\
\hline Unknown & $63(47.4 \%)$ & $58(13.6 \%)$ & & $15(11.3 \%)$ & \\
\hline Tumor size & & & $<0.001^{\star}$ & & 1 \\
\hline Yes & $4(3 \%)$ & 145 (33.9\%) & & $40(30.1 \%)$ & \\
\hline Chemotherapy & & & $<0.001^{*}$ & & 1 \\
\hline No & 78 (58.6\%) & $163(38.1 \%)$ & & 78 (58.6\%) & \\
\hline Yes & 55 (41.4\%) & 265 (61.9\%) & & 55 (41.4\%) & \\
\hline
\end{tabular}

Values are expressed as $\mathrm{n}(\%)$ unless otherwise indicated. *, Two-sided $\mathrm{P}$ values $<0.05$. 
Table S2 Patient and tumor characteristics of lung cancer patients grouped by surgery before and after propensity score matching $(\mathrm{N}=15,484)$

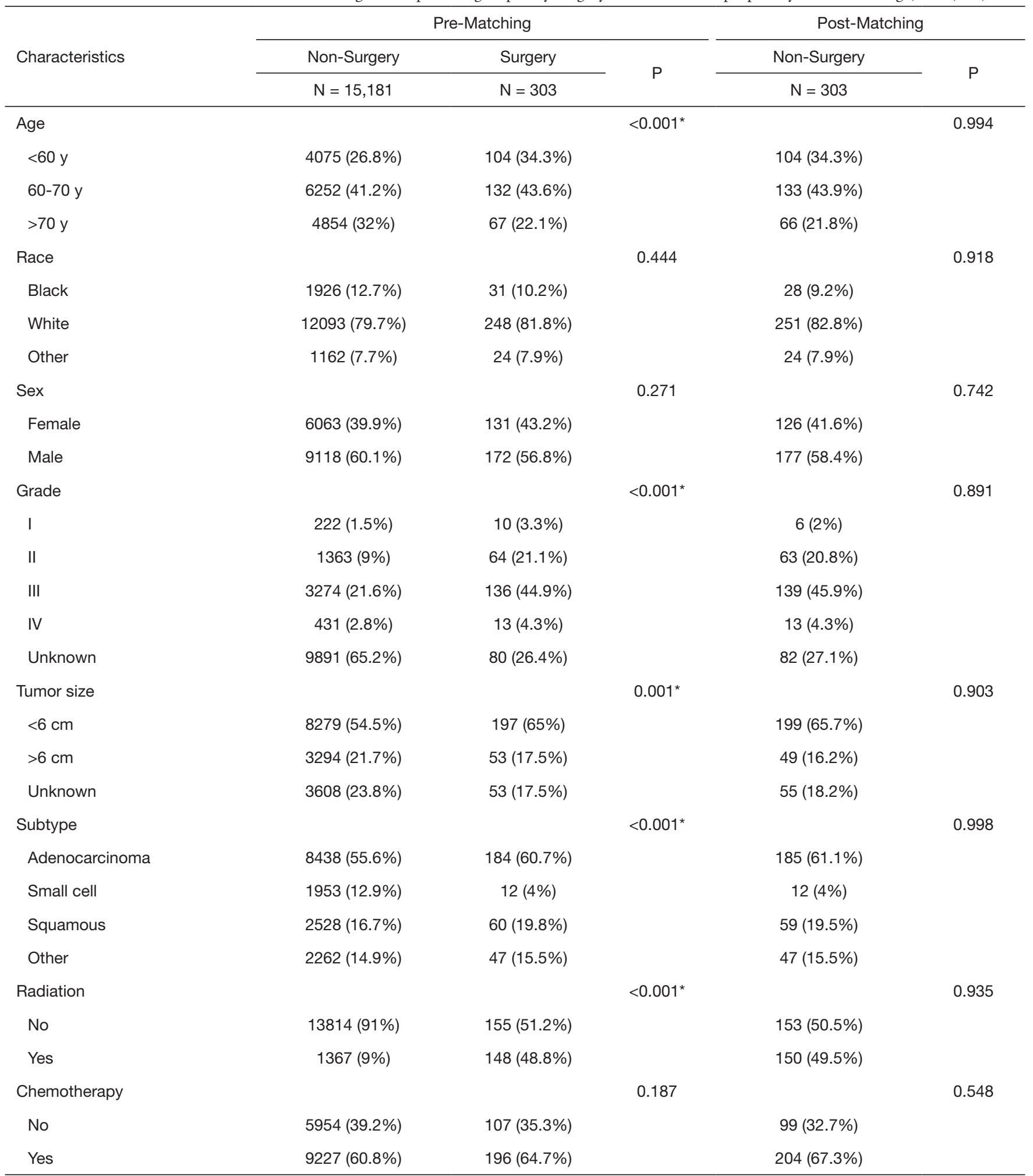

Values are expressed as $\mathrm{n}(\%)$ unless otherwise indicated. *, Two-sided $\mathrm{P}$ values $<0.05$. 
Table S3 Patient and tumor characteristics of kidney cancer patients grouped by surgery before and after propensity score matching $(\mathrm{N}=1,440)$

\begin{tabular}{|c|c|c|c|c|c|}
\hline \multirow{2}{*}{ Characteristics } & \multicolumn{3}{|c|}{ Pre-Matching } & \multicolumn{2}{|c|}{ Post-Matching } \\
\hline & $N=835$ & $N=605$ & $P$ & $N=605$ & $\mathrm{P}$ \\
\hline Age & & & $<0.001^{*}$ & & $0.005^{\star}$ \\
\hline$<65 y$ & 399 (47.8\%) & 391 (64.6\%) & & 342 (56.5\%) & \\
\hline Race & & & 0.387 & & 0.432 \\
\hline Black & 87 (10.4\%) & 60 (9.9\%) & & 67 (11.1\%) & \\
\hline White & 702 (84.1\%) & 501 (82.8\%) & & 504 (83.3\%) & \\
\hline Other & 46 (5.5\%) & 44 (7.3\%) & & 34 (5.6\%) & \\
\hline Male & 596 (71.4\%) & 420 (69.4\%) & & 432 (71.4\%) & \\
\hline Grade & & & $<0.001^{*}$ & & $<0.001^{*}$ \\
\hline I & 16 (1.9\%) & $10(1.7 \%)$ & & $13(2.1 \%)$ & \\
\hline II & 39 (4.7\%) & $127(21 \%)$ & & 36 (6\%) & \\
\hline III & 64 (7.7\%) & 223 (36.9\%) & & 51 (8.4\%) & \\
\hline IV & 20 (2.4\%) & $140(23.1 \%)$ & & $18(3 \%)$ & \\
\hline Unknown & $696(83.4 \%)$ & 105 (17.4\%) & & 487 (80.5\%) & \\
\hline Tumor size & & & $<0.001^{*}$ & & $<0.001^{*}$ \\
\hline Yes & $31(3.7 \%)$ & $121(20 \%)$ & & $31(5.1 \%)$ & \\
\hline Unknown & 649 (77.7\%) & $43(7.1 \%)$ & & 419 (69.3\%) & \\
\hline Radiation & & & $<0.001^{*}$ & & $<0.001^{*}$ \\
\hline No & 753 (90.2\%) & 228 (37.7\%) & & 541 (89.4\%) & \\
\hline Yes & 82 (9.8\%) & 377 (62.3\%) & & 64 (10.6\%) & \\
\hline Chemotherapy & & & 0.955 & & 0.272 \\
\hline No & 384 (46\%) & $280(46.3 \%)$ & & 260 (43\%) & \\
\hline Yes & 451 (54\%) & 325 (53.7\%) & & $345(57 \%)$ & \\
\hline
\end{tabular}

Values are expressed as $\mathrm{n}(\%)$ unless otherwise indicated. * , Two-sided $\mathrm{P}$ values $<0.05$. 
Table S4 Prognostic factors for overall survival in bladder cancer patients (N=561)

\begin{tabular}{|c|c|c|c|c|}
\hline Characteristics & \multicolumn{2}{|c|}{ Univariate } & \multicolumn{2}{|c|}{ Multivariate } \\
\hline \multicolumn{5}{|l|}{ Age } \\
\hline$<75 y$ & Reference & & Reference & \\
\hline$>75 y$ & $1.31(1.05-1.65)$ & $0.019^{*}$ & $1.25(0.99-1.58)$ & 0.062 \\
\hline Black & Reference & & & \\
\hline White & $0.77(0.58-1.01)$ & 0.06 & & \\
\hline Other & $0.66(0.41-1.07)$ & 0.092 & & \\
\hline \multicolumn{5}{|l|}{ Sex } \\
\hline \multicolumn{5}{|l|}{ Tumor size } \\
\hline$<5 \mathrm{~cm}$ & Reference & & Reference & \\
\hline$>5 \mathrm{~cm}$ & $1.51(1.13-2)$ & $0.005^{*}$ & $1.61(1.21-2.14)$ & $0.001^{*}$ \\
\hline Unknown & $1.59(1.24-2.04)$ & $<0.001^{*}$ & $1.58(1.23-2.04)$ & $<0.001^{*}$ \\
\hline \multicolumn{5}{|l|}{ Grade } \\
\hline I & Reference & & Reference & \\
\hline II & $0.43(0.15-1.24)$ & 0.12 & $0.77(0.26-2.27)$ & 0.631 \\
\hline III & $0.37(0.15-0.92)$ & $0.033^{*}$ & $0.77(0.31-1.96)$ & 0.586 \\
\hline \multicolumn{5}{|l|}{ Radiation } \\
\hline No & Reference & & & \\
\hline Yes & $0.91(0.74-1.13)$ & 0.39 & & \\
\hline \multicolumn{5}{|l|}{ Chemotherapy } \\
\hline No & Reference & & Reference & \\
\hline Yes & $0.29(0.24-0.34)$ & $<0.001^{*}$ & $0.29(0.24-0.36)$ & $<0.001^{*}$ \\
\hline
\end{tabular}

Values are expressed as hazard ratios $(\mathrm{HR})$ with $95 \%$ confidence intervals $(\mathrm{Cl})$ unless otherwise indicated. *, Two-sided $\mathrm{P}$ values $<0.05$. 
Table S5 Prognostic factors for overall survival in lung cancer patients $(\mathrm{N}=15,484)$

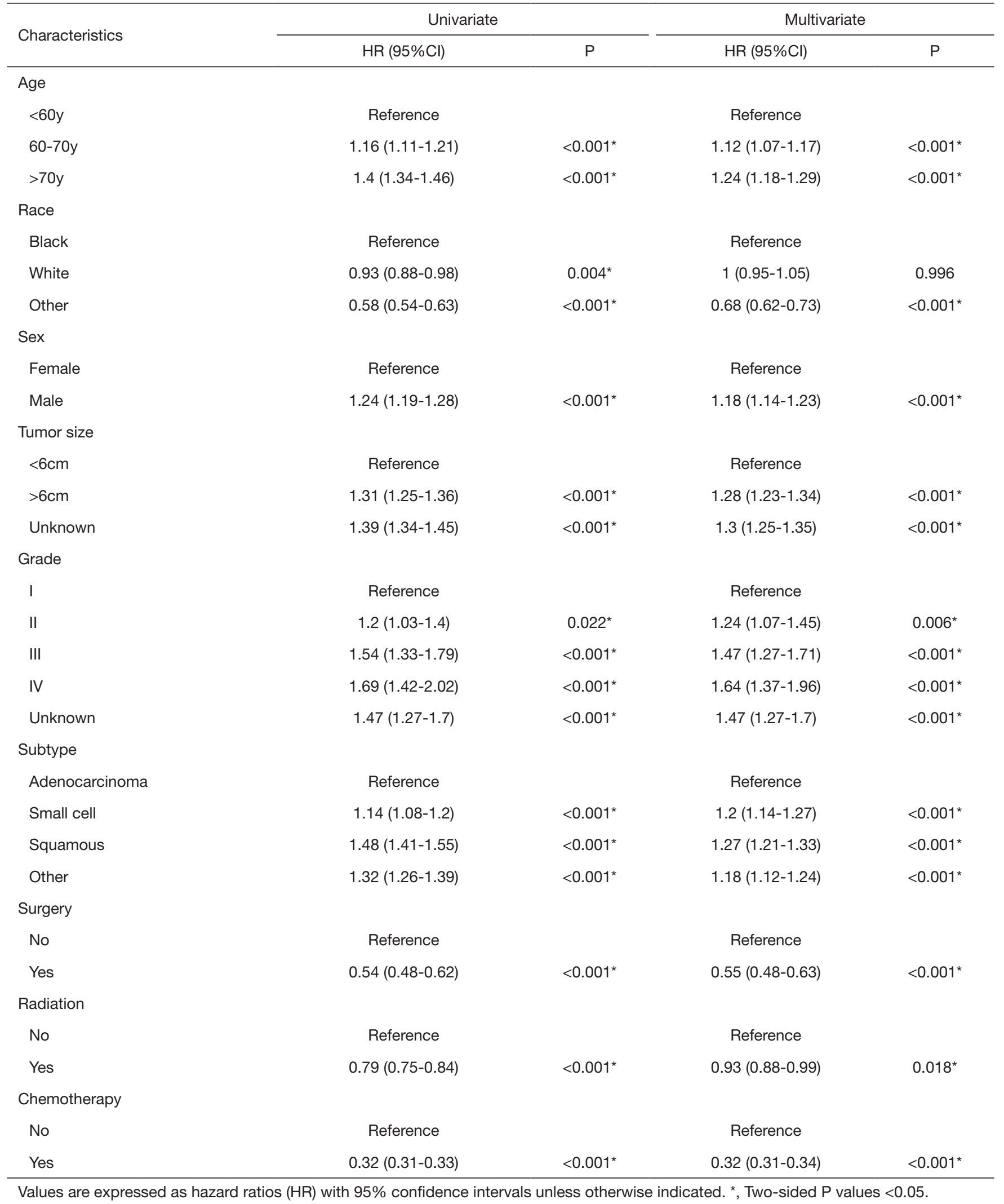


Table S6 Prognostic factors for overall survival in kidney cancer patients $(\mathrm{N}=1,440)$

\begin{tabular}{|c|c|c|c|c|}
\hline Characteristics & \multicolumn{2}{|c|}{ Univariate } & \multicolumn{2}{|c|}{ Multivariate } \\
\hline \multicolumn{5}{|l|}{ Age } \\
\hline$<65 y$ & Reference & & Reference & \\
\hline$>65 y$ & $1.58(1.39-1.78)$ & $<0.001^{*}$ & $1.39(1.23-1.58)$ & $<0.001^{*}$ \\
\hline Black & Reference & & & \\
\hline White & $0.85(0.7-1.04)$ & 0.115 & & \\
\hline Other & $0.82(0.6-1.12)$ & 0.208 & & \\
\hline \multicolumn{5}{|l|}{ Sex } \\
\hline \multicolumn{5}{|l|}{ Tumor size } \\
\hline$<4.5 \mathrm{~cm}$ & Reference & & Reference & \\
\hline$>4.5 \mathrm{~cm}$ & $0.87(0.74-1.02)$ & 0.079 & $1.11(0.95-1.31)$ & 0.188 \\
\hline Unknown & $1.55(1.25-1.92)$ & $<0.001^{*}$ & $1.22(0.98-1.51)$ & 0.069 \\
\hline \multicolumn{5}{|l|}{ Grade } \\
\hline I & Reference & & & \\
\hline II & $0.78(0.45-1.36)$ & 0.388 & & \\
\hline III & $1.18(0.7-2.01)$ & 0.529 & & \\
\hline \multicolumn{5}{|l|}{ Sarcomatoid } \\
\hline Unknown & $2.32(2.02-2.66)$ & $<0.001^{\star}$ & $1.1(0.92-1.32)$ & 0.284 \\
\hline \multicolumn{5}{|l|}{ Surgery } \\
\hline No & Reference & & Reference & \\
\hline Yes & $0.37(0.32-0.42)$ & $<0.001^{*}$ & $0.34(0.27-0.41)$ & $<0.001^{*}$ \\
\hline \multicolumn{5}{|l|}{ Radiation } \\
\hline No & Reference & & Reference & \\
\hline Yes & $0.56(0.49-0.64)$ & $<0.001^{\star}$ & $1.02(0.87-1.2)$ & 0.811 \\
\hline \multicolumn{5}{|l|}{ Chemotherapy } \\
\hline No & Reference & & Reference & \\
\hline Yes & $0.81(0.71-0.91)$ & $0.001^{*}$ & $0.7(0.61-0.79)$ & $<0.001^{\star}$ \\
\hline
\end{tabular}

